\title{
Theoretical Study of Phosphoethanolamine: A Synthetic Anticancer Agent with Broad Antitumor Activity
}

\author{
Vitor Prates Lorenzo, ${ }^{1,2}$ Francisco Jaime Bezerra Mendonça Júnior, ${ }^{3}$ \\ José Maria Barbosa Filho, ${ }^{1}$ Luciana Scotti, ${ }^{1}$ and Marcus Tullius Scotti ${ }^{1}$ \\ ${ }^{1}$ Postgraduate Program in Natural Products and Synthetic Bioactive, Federal University of Paraíba, 58051-900 João Pessoa, PB, Brazil \\ ${ }^{2}$ Federal Institute of Sertão Pernambucano, 56314-520 Petrolina, PE, Brazil \\ ${ }^{3}$ Laboratory of Synthesis and Vectorization of Molecules, State University of Paraíba, 58020-540 João Pessoa, PB, Brazil
}

Correspondence should be addressed to Marcus Tullius Scotti; mtscotti@gmail.com

Received 4 February 2016; Revised 24 April 2016; Accepted 7 June 2016

Academic Editor: Antreas Afantitis

Copyright (C) 2016 Vitor Prates Lorenzo et al. This is an open access article distributed under the Creative Commons Attribution License, which permits unrestricted use, distribution, and reproduction in any medium, provided the original work is properly cited.

\begin{abstract}
Cancer is a major public health problem with limited success of available treatments, pointing to the need for new strategies to be developed. Phosphoethanolamine exhibits broad antitumor activity in a variety of tumor cells and potent inhibitor effects on tumor progress in vivo. Once-used organophosphates inhibit acetylcholinesterase (AChE), resulting in toxic effects to the user. As this group is present in phosphoethanolamine, we perform prediction of the in silico metabolism of phosphoethanolamine and submit this series to a docking study on AChE. A total of 10 metabolites were indicated by the prediction, including ammonia

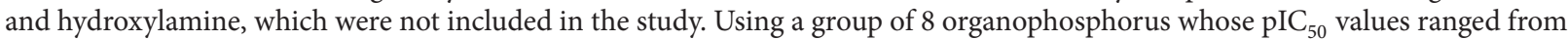
5.92 to 9.47 as template, we observed that no compound present in the phosphoethanolamine series had a binding energy lower than that of organophosphorus, suggesting that the series has low inhibitory power on AChE. In light of this, we conclude that phosphoethanolamine and its predicted metabolites do not significantly inhibit AChE to cause a cholinergic crisis. This finding highlights the importance of investigating this compound as lead for potential anticancer agents.
\end{abstract}

\section{Introduction}

Cancer is a major public health problem in many parts of the world, representing the second leading cause of death in the Western world. The number of individuals diagnosed with cancer increases each year, with millions of deaths. For example, in 2012, 8.2 million people died of cancerapproximately $13 \%$ of all deaths worldwide. Furthermore, it is predicted that cancer will increase from 10 million new cases in 2000 to 15 million in 2020, an increase of 50\% [1-3]. The limited successes of available treatments for cancer mean that new strategies need to be developed $[4,5]$.

Phospholipids are present in tissues and there is a special scientific interest in the elucidation of their role in the treatment of cancer. Phosphoethanolamine is a precursor of phosphatidylcholine and phosphatidylethanolamine, both of which are involved in the turnover of cell membrane phospholipids. Both of these phospholipids take part in lipid signaling pathways, either acting as ligands or generating intermediate substrates [6-8].

A class of potential synthetic antineoplastic phospholipids such as alkylphospholipids represents a promising treatment for cancer. Ether lipids, as this class is collectively termed, have been shown to reduce the synthesis of phosphatidylcholine in cancer cells, interfering with phospholipid-induced apoptosis. Miltefosine (hexadecylphosphocholine) is an analogous lipid compound that is used for control of cutaneous metastases of human malignant melanoma [8-10].

Studies have shown that synthetic phosphoethanolamine exhibits broad antitumor activity in a variety of tumor cells and potent inhibitor effects on tumor progress in vivo. Other actions of phosphoethanolamine include antiproliferative and proapoptotic effects on melanoma cells [8], activity in the renal carcinoma model [11], apoptosis in human breast cancer 
MCF-7 cells via the mitochondrial pathway [12], inhibition of tumor growth, and increase of animals lifespan without causing liver or hematological toxicity $[13,14]$.

Organophosphates are organic compounds commonly used as pesticides. Their ability to inhibit acetylcholinesterase (AChE) is directly related to the toxicity of this group of molecules. Human AChEs are a class of enzymes whose biological function is to catalyze the hydrolysis of the neurotransmitter acetylcholine in the terminal nerve junction. The inhibition of AChE by organophosphorus involves phosphorylation of active binding site blocking acetylcholine hydrolysis, through attack of hydroxyl group from serine to nucleophilic phosphorus [15-18].

The presence of a phosphate group in phosphoethanolamine could increase the toxicity of this potential anticancer agent or its metabolites, generated after biotransformation. In light of this, the present work predicts the in silico metabolism of phosphoethanolamine and evaluates the affinity of the compound, three analogues, and its metabolites to $\mathrm{AChE}$ through molecular docking.

\section{Materials and Methods}

2.1. In Silico Metabolism. For prediction of metabolism, Metabolizer version 15.6.8, part of ChemAxon's JChem package (https://www.chemaxon.com/), was used. The software transforms the substrate according to generic transformations from a current biotransformation library. The structure of phosphoethanolamine was drawn in the program and then calculated according to default configuration.

Metabolizer calculates global accumulation by considering all alternative metabolic routes to the metabolite. The ones with highest global accumulations are considered major metabolites.

2.2. Physicochemical Properties. Determination of $\log P$, $\log D$, and molar refractivity were obtained using Marvin Sketch 14.12.8.0 while electrostatic surface was calculated using Marvin Space 14.12.8.0; both are part of ChemAxon's JChem package (https://www.chemaxon.com/). All four calculations used default configuration.

The $\log P$ plugin calculates the octanol/water partition coefficient, which is used in rational drug design as a measure of molecular hydrophobicity. $\log D$ is important in compounds with ionizable groups, once ionization of those groups; thus the ratio of the ionic forms depends on the $\mathrm{pH} . \log \mathrm{D}$ represents the compounds at any $\mathrm{pH}$ value. Calculations are based on a pool of fragments predefined in the calculator. The partition value of a molecule is the sum of the fragment values present in the molecule. Weighted method was used, which is a combination of three partition calculations VG, KLOP, and PHYPROSP [19-21].

Molar refractivity is strongly related to molar volume and London dispersive forces that has important effect on drugreceptor interaction. Calculation was based on the atomic method proposed by Viswanadhan et al. [19]. For electrostatic parameters, van der Walls surface was determined for each compound. Then, electrostatic potential was selected as color type and exported.
2.3. VolSurf Descriptors. Three-dimensional structures (3D) were used as input data in the VolSurf+ program v. 1.0.7 [20] and were subjected to molecular interaction fields (MIF) [20] to generate descriptors using the following probes: N1 (amide nitrogen-hydrogen bond donor probe), O (carbonyl oxygen-hydrogen bond acceptor probe), $\mathrm{OH} 2$ (water probe), and DRY (hydrophobic probe). Additional non-MIF-derived descriptors were generated to create a total of 128 descriptors [20]. VolSurf descriptors have been previously used to predict the inhibitory actions of alkaloids against monoamine oxidase B (MAO-B) [21].

CACO2 and SKIN are computed via PLS model derived by fitting VolSurf+ descriptors to experimental data. The values are only qualitative for $\mathrm{CACO} 2$ and quantitative $(\mathrm{cm} / \mathrm{h})$ for skin.

Log of the Blood-Brain Barrier (LgBB) distribution indicates permeability level. Values lower than -0.5 indicate very poor brain permeation while values greater than 0.5 indicate high brain permeation. Volume of Distribution (VD) is computed via a PLS model derived by fitting VolSurf+ descriptors to $-\log$ of experimental data on volume of distribution (Litre/Kg).

Metabolic Stability (MetStab) is percentage of the remaining compound after incubation with human CYP3A4 enzyme. Values greater than 50 indicate stable behavior (100 is the maximum stability); values lower than 50 are less precise and indicate metabolic instability.

2.4. Docking. The structure of acetylcholinesterase (PDB ID 2ACE) [22] was downloaded from the Protein Data Bank (http://www.rcsb.org/pdb/home/home.do). Molecular structures were submitted to molecular docking using the Molegro Virtual Docker, v. 6.0.1 (MVD) [23]. All of the water molecules were deleted from the enzyme structure and the enzyme and compound structures were prepared using the same default parameter settings in the software package (score function: MolDock score; ligand evaluation: Internal ES, Internal HBond, Sp2-Sp2 Torsions, all checked; number of runs: 10; search algorithm: MolDock SE; maximum interactions: 1500; max. population size: 50; max. steps: 300; neighbor distance factor: 1.00; and max. number of poses returned: 5). The docking procedure was performed using a GRID of $15 \AA$ in radius and 0.30 in resolution to cover the ligand-binding site of the acetylcholinesterase structure [24].

A group of 8 organophosphorus [25], whose $\mathrm{IC}_{50}$ values ranged from $0.34 \mathrm{nM}$ to $1.2 \mu \mathrm{M}$ ( $\mathrm{pIC}_{50}$ values, $-\log \mathrm{IC}_{50}$ (mol/L), from 5.92 to 9.47 ), were used to evaluate the binding energy of phosphoethanolamine and its metabolites to AChE (Table 1).

\section{Results and Discussion}

The Metabolizer software is useful for enumeration of the metabolites of drugs and the prediction of their likelihood. A total of 10 metabolites were generated, including ammonia and hydroxylamine, which were not included in the study due to their simple structures. The structure of the selected metabolites and their respective global accumulation values are presented in Figure 1. 
<smiles>O=P(O)(O)CCNO</smiles>

M1-GA $0.0 \%$<smiles>O=P(O)(O)CCO</smiles>

M5-GA 1.3\%<smiles>O=C(O)CP(=O)(O)O</smiles>

M2-GA $65.8 \%$<smiles>O=P(O)(O)CC(O)NO</smiles>

M6-GA 0.0\%<smiles>NC(=O)CP(=O)(O)O</smiles>

M3-GA $0.0 \%$<smiles>NC(O)CP(=O)(O)O</smiles>

M7-GA $0.0 \%$<smiles>O=CCP(=O)(O)O</smiles>

M4-GA $0.0 \%$<smiles>O=C(CP(=O)(O)O)NO</smiles>

M8-GA 15.5\%

FIgURE 1: Structure of phosphoethanolamine metabolites and their respective GA (global accumulation). The highest GA for M2 indicates that it is the major metabolite.

TABLE 1: Calculated $\log P$ and molar refractivity of phosphoethanolamine and analogues, phosphoethanolamine metabolites, and group of 8 organophosphorus compounds. Pho: phosphoethanolamine; Pho_01 to Pho_03: phosphoethanolamine analogues; M1 to M8: phosphoethanolamine metabolites; O1: Chlorpyrifos-Oxon; O2: $\mathrm{O}, \mathrm{O}-$ dibutyl O-(2,2-dichlorovinyl) Phosphate; O3: Paraoxon; O4: Cyclic Tolyl Saligenin Phosphate; O5: Diisopropyl Phosphorofluoridate; O6: Cyclic Phenyl Saligenin Phosphate; O7: Dichlorvos; O8: Trichlorfon.

\begin{tabular}{lcc}
\hline Compound & clog $P$ & Molar refractivity \\
\hline Pho & -2.05 & 25.25 \\
Pho_01 & -0.26 & 43.71 \\
Pho_02 & 1.24 & 63.28 \\
Pho_03 & 2.35 & 73.77 \\
M1 & -2.02 & 37.51 \\
M2 & -1.60 & 23.63 \\
M3 & -2.40 & 25.46 \\
M4 & -1.87 & 22.71 \\
M5 & -1.95 & 23.59 \\
M6 & -2.41 & 38.54 \\
M7 & -2.45 & 26.28 \\
M8 & -2.52 & 27.22 \\
O1 & 3.78 & 75.46 \\
O2 & 3.18 & 66.21 \\
O3 & 3.69 & 71.25 \\
O4 & 1.37 & 52.19 \\
O5 & 1.76 & 40.89 \\
O6 & 4.02 & 79.94 \\
O7 & 2.43 & 63.69 \\
O8 & 1.14 & 47.59 \\
\hline
\end{tabular}

Values of calculated $\log P(\operatorname{cog} P)$ and molar refractivity of phosphoethanolamine and analogues (Figure 2), phosphoethanolamine metabolites (M1 to M8), and a group of 8 organophosphorus compounds, used as parameter to evaluate phosphoethanolamine and derivatives (analogues and metabolites), are displayed in Table $1 . \log D$ of phosphoethanolamine and derivatives are displayed in Figure 3.

Electrostatic properties of phosphoethanolamine and derivatives are represented in Figure 4. A high electronic density is observed in phosphate and amine group in phosphoethanolamine; the hydrogen linked to electronegative atoms presents low electronic density (blue color). An increase of polarity (red color) is well observed in metabolites, increasing molecular polarity.

The group of 8 organophosphorus compounds [26] was submitted to molecular docking and their energy binding and $\mathrm{pIC}_{50}$ values (Table 2 ) were used as parameters to evaluate the phosphoethanolamine series. Chlorpyrifos-Oxon showed the lowest binding energy value of -107.9 MolDock energy, corroborated by a smaller $\mathrm{pIC}_{50}$ value. A good correspondence between experimental and docking data was observed in the analysis of the 4 compounds with lower $\mathrm{pIC}_{50}$ values, all of which had energy values under -100 MolDock energy (Table 2). The coefficient of determination $\left(R^{2}\right)$ was 0.68 , indicating a significant correlation (Figure 5).

High binding energy values (Table 3) for phosphoethanolamine and its metabolites indicated an inferior interaction with AChE compared to the organophosphorus group 
TABLE 2: Group of organophosphorus compounds used as parameters, with structure and name, $\mathrm{pIC}_{50}\left(-\log \mathrm{IC}_{50}(\mathrm{~mol} / \mathrm{L})\right)$, and binding energy.

Compound
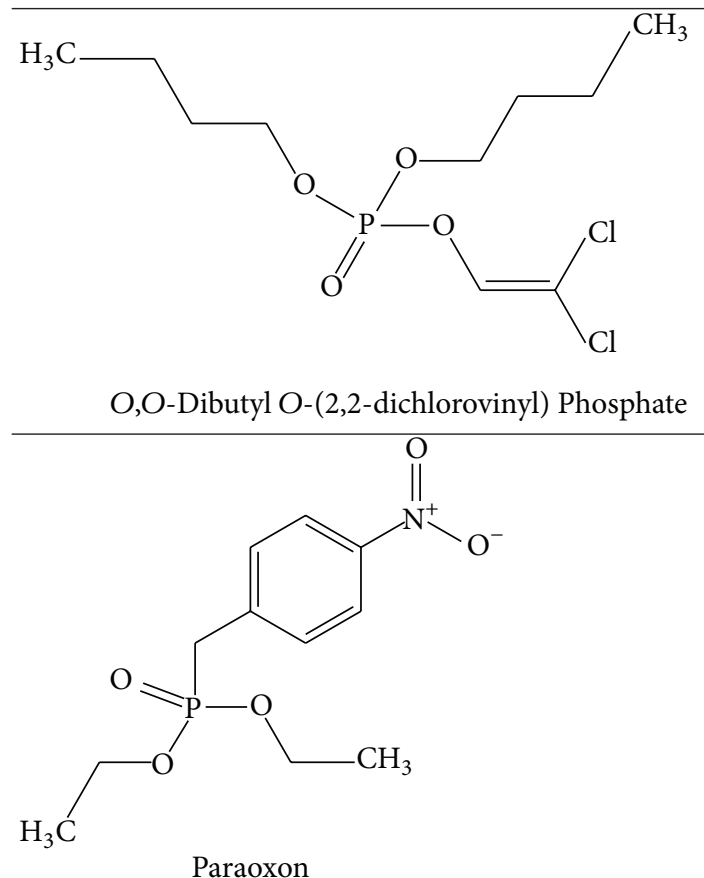<smiles>Cc1ccccc1OP1(=O)OCc2ccccc2O1</smiles>

Cyclic Tolyl Saligenin Phosphate

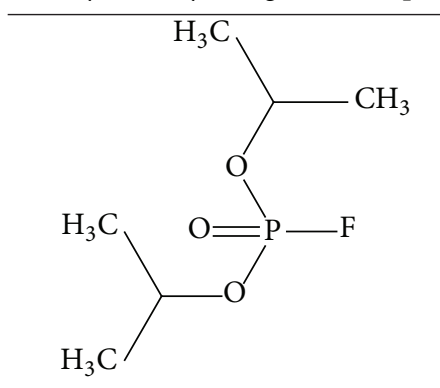

6.72 
TABle 2: Continued.

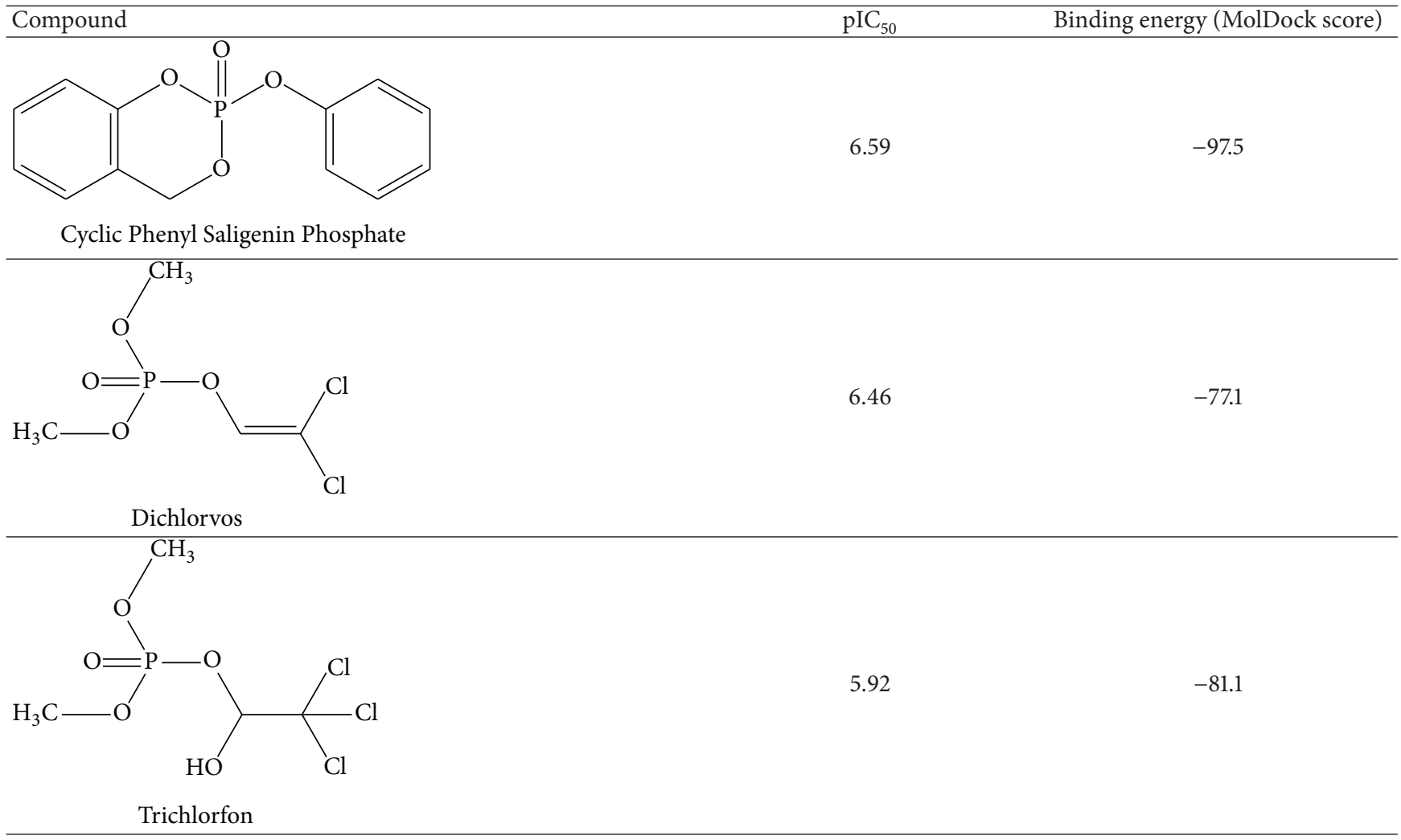<smiles>CCOP(=O)(CCN)OCC</smiles>

Pho

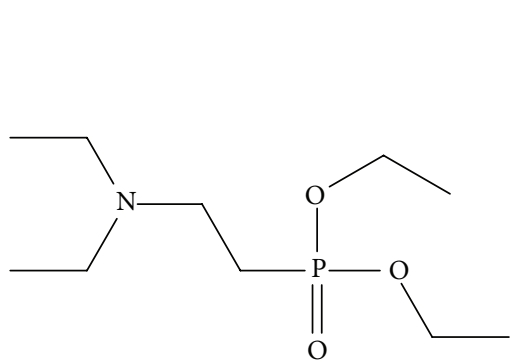

Pho_02<smiles>NCCP(=O)(Oc1ccccc1)Oc1ccccc1</smiles>

Pho_03

FIGURE 2: Structure of phosphoethanolamine (Pho) and three analogues (Pho_01 to Pho_03), substituting hydroxyl group on phosphate and amine group in Pho_02.

(Table 3). Phosphoethanolamine had a low energy binding value of -59.2 MolDock score, indicating a weak interaction between the molecule and the receptor, thus suggesting a low toxicity for this enzyme. In silico metabolism indicated M2 as major metabolite (Figure 1), as the binding energy of this compound was one of the lowest in the series. The other metabolite with considerable abundance was M8, with a -72.3 MolDock score energy. This was the highest value among the metabolites but lower than any organophosphorus compound used as a template, confirming the weak interaction of phosphoethanolamine and its metabolites with AChE. The three proposed analogues show energy binding value lower than phosphoethanolamine, increasing interaction with AChE.

Some molecular descriptors are parameters appropriable to evaluate ADME process and drug behavior (Table 4). Five molecular VolSurf descriptors were selected in order to evaluate permeability (CACO2 cells and SKIN), distribution (LgBB and VD), and stability (MetStab). Phosphoethanolamine and metabolites present low permeability 


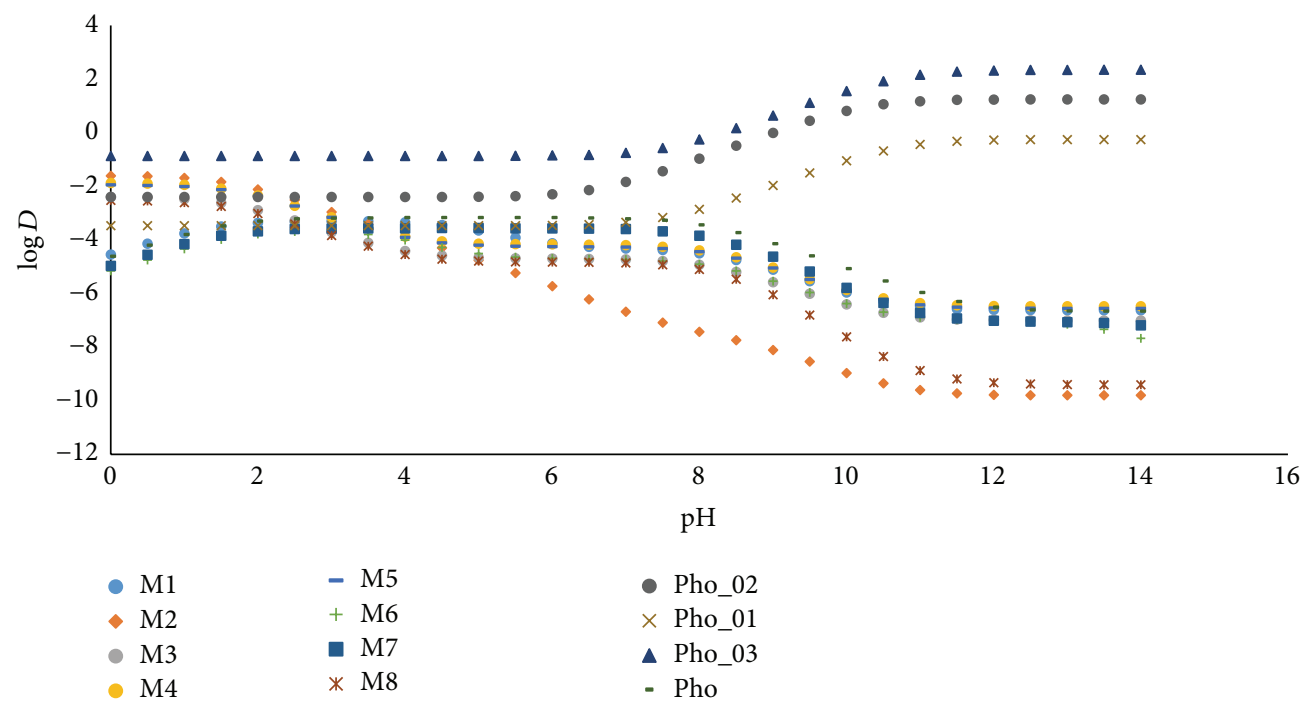

FIgURE 3: $\log D$ of phosphoethanolamine (Pho), analogues (Pho_01 to Pho_03), and metabolites (M1 to M8) in different pH values.
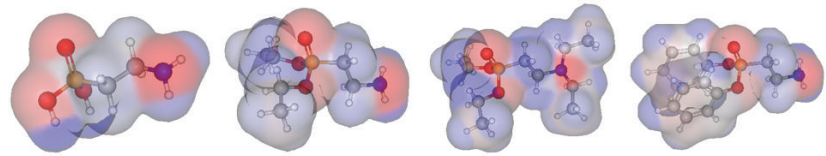

Pho

Pho_01
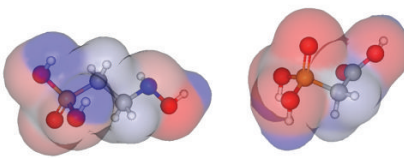

Pho_02

Pho_03

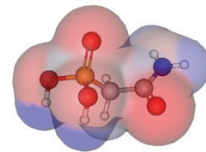

M3

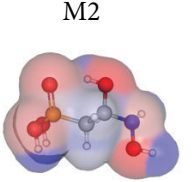

M6

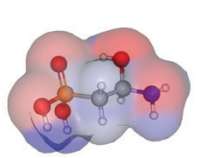

M7

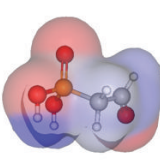

M4

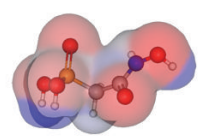

M8

FIgURE 4: Electrostatics properties of phosphoethanolamine and derivatives. Red color indicates regions with high electronic density.

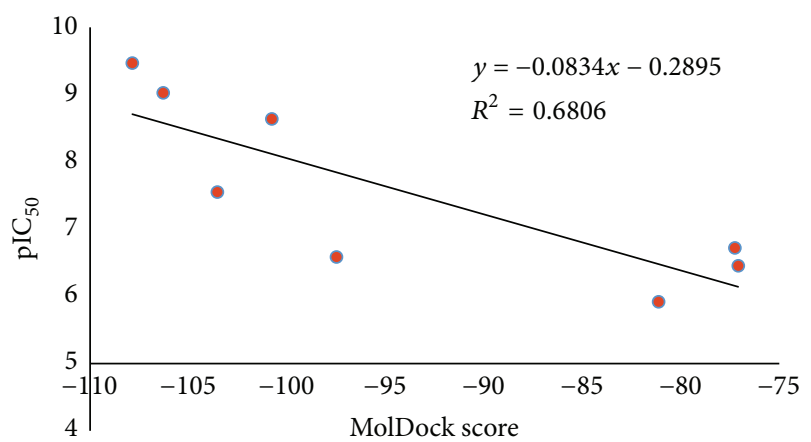

FIGURE 5: Correlation between binding energy value in MolDock score ( $x$-axis) and experimental pIC $_{50}$ values ( $y$-axis) of organophosphorus group. The coefficient of determination $\left(R^{2}\right)$ is also indicated.

TABLE 3: Combine binding energy values in MolDock score of phosphoethanolamine (Pho), phosphoethanolamine analogues (Pho_01 to Pho_03), phosphoethanolamine metabolites (M1 to M8), and organophosphorus group (O1 to $\mathrm{O} 8$ ).

\begin{tabular}{lc}
\hline Pho & -59.2 \\
Pho_01 & -76.9 \\
Pho_02 & -96.2 \\
Pho_03 & -114.1 \\
M1 & -63.5 \\
M2 & -61.0 \\
M3 & -63.2 \\
M4 & -58.0 \\
M5 & -59.6 \\
M6 & -67.4 \\
M7 & -63.2 \\
M8 & -72.3 \\
O1 & -107.9 \\
O2 & -106.3 \\
O3 & -100.8 \\
O4 & -103.5 \\
O5 & -77.2 \\
O6 & -97.5 \\
O7 & -77.1 \\
O8 & -81.1 \\
\hline
\end{tabular}

Pho: phosphoethanolamine; Pho_01 to Pho_03: phosphoethanolamine analogues; M1 to M8: phosphoethanolamine metabolites; O1: ChlorpyrifosOxon; O2: O,O-dibutyl O-(2,2-dichlorovinyl) Phosphate; O3: Paraoxon; O4: Cyclic Tolyl Saligenin Phosphate; O5: Diisopropyl Phosphorofluoridate; O6: Cyclic Phenyl Saligenin Phosphate; O7: Dichlorvos; and O8: Trichlorfon.

through CACO2 cells and SKIN. The analogues showed a better comparative performance, probably related to their lower polarity.

An unsatisfactory distribution for phosphoethanolamine and derivatives in systemic circulation and central nervous system was also observed, whereas analogues display better 
TABLE 4: VolSurf molecular descriptors appropriable to evaluate ADME process and drug behavior. CACO2 cells and SKIN permeability, log blood-brain barrier distribution (LgBB), volume of distribution (VD), and metabolic stability (MetStab).

\begin{tabular}{|c|c|c|c|c|c|}
\hline Compound & $\mathrm{CACO} 2$ & SKIN & $\operatorname{LgBB}$ & VD & MetStab \\
\hline Pho & -1.03805 & -6.81425 & -2.00629 & -0.1297 & 100 \\
\hline Pho_01 & 0.352823 & -4.14639 & 0.068157 & 0.240273 & 100 \\
\hline Pho_02 & 1.10666 & -2.3428 & 0.375648 & 0.27598 & 73.9335 \\
\hline Pho_03 & 0.53779 & -3.05418 & 0.281418 & 0.155534 & 84.9974 \\
\hline M1 & -1.44627 & -7.72323 & -2.4985 & -0.24442 & 100 \\
\hline M2 & -1.38436 & -6.70337 & -2.17963 & -0.32468 & 100 \\
\hline M3 & -1.3003 & -6.89743 & -2.12005 & -0.11547 & 100 \\
\hline M4 & -0.82973 & -6.05096 & -1.46413 & -0.03631 & 100 \\
\hline M5 & -1.09326 & -6.60327 & -2.09054 & -0.3334 & 100 \\
\hline M6 & -1.89772 & -10.902 & -2.98507 & -0.17428 & 100 \\
\hline M7 & -1.43742 & -8.2624 & -2.53329 & 0.024709 & 100 \\
\hline M8 & -1.58487 & -8.78139 & -2.44954 & -0.01373 & 100 \\
\hline $\mathrm{O} 1$ & 1.37183 & -1.79192 & 0.289113 & 0.127351 & 39.3059 \\
\hline $\mathrm{O} 2$ & 1.28518 & -1.60439 & 0.442147 & -0.00769 & 49.6523 \\
\hline $\mathrm{O} 3$ & 1.34774 & -1.56177 & 0.431478 & 0.056206 & 44.2688 \\
\hline O4 & 1.2689 & -2.09574 & 0.411952 & 0.138814 & 75.1341 \\
\hline O5 & 1.08652 & -2.34342 & 0.176429 & -0.08398 & 87.1393 \\
\hline O6 & 1.53633 & -1.22958 & 0.486752 & 0.033381 & 28.1952 \\
\hline O7 & 1.0289 & -2.50402 & 0.109418 & -0.04239 & 58.5821 \\
\hline $\mathrm{O} 8$ & 0.957486 & -3.17353 & -0.0024 & 0.211614 & 86.3035 \\
\hline
\end{tabular}

results again. About stability, both phosphoethanolamine and metabolites show maximum stability level.

\section{Conclusion}

This theoretical study suggests that a series composed of phosphoethanolamine and its metabolites exhibit low affinity to the enzyme AChE, suggesting low neurotoxicity during the use and biotransformation of this anticancer compound.

A docking study corroborated the results of experimental enzymatic inhibitory values of AChE and was executed in comparison to a group of 8 organophosphorus compounds whose $\mathrm{pIC}_{50}$ values ranged from 5.92 to 9.47. We observed that no compound of the phosphoethanolamine series showed energy levels close to the template group, indicating a weak interaction with AChE.

In light of this, we conclude that phosphoethanolamine and its predicted metabolites do not significantly inhibit AChE to cause a cholinergic crisis, as organophosphorus usually act, indicating a low neurotoxicity potential, highlighting the interest in further investigating this compound as a potential lead for future anticancer agents.

\section{Competing Interests}

The authors declare that there is no conflict of interests regarding the publication of this paper.

\section{References}

[1] C. Dive and J. A. Hickman, "Drug-target interactions: only the first step in the commitment to a programmed cell death?" British Journal of Cancer, vol. 64, no. 1, pp. 192-196, 1991.
[2] WHO, 2016, http://www.who.int/cancer/en/.

[3] WHO, 2003, http://www.who.int/cancer/en/.

[4] R. Ortiz, C. Melguizo, J. Prados et al., "New gene therapy strategies for cancer treatment: a review of recent patents," Recent Patents on Anti-Cancer Drug Discovery, vol. 7, no. 3, pp. 297-312, 2012.

[5] C. E. Desantis, C. C. Lin, A. B. Mariotto et al., "Cancer treatment and survivorship statistics, 2014," CA: Cancer Journal for Clinicians, vol. 64, no. 4, pp. 252-271, 2012.

[6] D. W. Ellison, M. F. Beal, and J. B. Martin, "Phosphoethanolamine and ethanolamine are decreased in Alzheimer's disease and Huntington's disease," Brain Research, vol. 417, no. 2, pp. 389-392, 1987.

[7] K. M. Eyster, “The membrane and lipids as integral participants in signal transduction: lipid signal transduction for the nonlipid biochemist," Advances in Physiology Education, vol. 31, no. 1, pp. 5-16, 2007.

[8] A. K. Ferreira, R. Meneguelo, S. C. Neto, G. O. Chierice, and D. A. Maria, "Synthetic phosphoethanolamine induces apoptosis through caspase-3 pathway by decreasing expression of Bax/Bad protein and changes cell cycle in melanoma," Journal of Cancer Science and Therapy, vol. 3, no. 3, pp. 53-59, 2011.

[9] A. H. van der Luit, S. R. Vink, J. B. Klarenbeek et al., "A new class of anticancer alkylphospholipids uses lipid rafts as membrane gateways to induce apoptosis in lymphoma cells," Molecular Cancer Therapeutics, vol. 6, no. 8, pp. 2337-2345, 2007.

[10] K. Danker, W. Reutter, and G. Semini, "Glycosidated phospholipids: uncoupling of signalling pathways at the plasma membrane," British Journal of Pharmacology, vol. 160, no. 1, pp. 36-47, 2010.

[11] A. K. Ferreira, B. A. A. Santana-Lemos, E. M. Rego, O. M. R. Filho, G. O. Chierice, and D. A. Maria, "Synthetic phosphoethanolamine has in vitro and in vivo anti-leukemia effects," British Journal of Cancer, vol. 109, no. 11, pp. 2819-2828, 2013. 
[12] A. K. Ferreira, R. Meneguelo, A. Pereira, O. M. R. Filho, G. O. Chierice, and D. A. Maria, "Synthetic phosphoethanolamine induces cell cycle arrest and apoptosis in human breast cancer MCF-7 cells through the mitochondrial pathway," Biomedicine and Pharmacotherapy, vol. 67, no. 6, pp. 481-487, 2013.

[13] A. K. Ferreira, R. Meneguelo, A. Pereira, O. M. R. Filho, G. O. Chierice, and D. A. Maria, "Anticancer effects of synthetic phosphoethanolamine on Ehrlich ascites tumor: an experimental study," Anticancer Research, vol. 32, no. 1, pp. 95-104, 2012.

[14] A. K. Ferreira, V. M. Freitas, D. Levy et al., "Anti-angiogenic and anti-metastatic activity of synthetic phosphoethanolamine," PLoS ONE, vol. 8, no. 3, Article ID e57937, 3 pages, 2013.

[15] A. K. Sharma, K. Gaur, R. K. Tiwari, and M. S. Gaur, "Computational interaction analysis of organophosphorus pesticides with different metabolic proteins in humans," Journal of Biomedical Research, vol. 25, no. 5, pp. 335-347, 2011.

[16] G. Ramanjaneyulu, C. Srinivasulu, R. Seenaiah, A. Ramya, and B. R. Reddy, "Docking studies of Endosulfan and its analogues on Human Acetylcholine esterase," International Journal of Research in Biological Sciences, vol. 4, no. 2, pp. 49-54, 2014.

[17] J. GladiesKezia, K. SewaliGhosh, and J. C. Priyakumari, "Docking studies on acetylcholinesterase with methylparathion," International Journal of Engineering Research \& Technology, vol. 2, no. 11, 2013.

[18] T. H. Lugokenski, P. Gubert, D. C. Bueno et al., "Effect of different oximes on rat and human cholinesterases inhibited by methamidophos: a comparative in vitro and in silico study," Basic and Clinical Pharmacology and Toxicology, vol. 111, no. 6, pp. 362-370, 2012.

[19] V. N. Viswanadhan, A. K. Ghose, G. R. Revankar, and R. K. Robins, "Atomic physicochemical parameters for three dimensional structure directed quantitative structure-activity relationships. 4. Additional parameters for hydrophobic and dispersive interactions and their application for an automated superposition of certain naturally occurring nucleoside antibiotics," Journal of Chemical Information and Computer Sciences, vol. 29, pp. 163-172, 1989.

[20] G. Cruciani, P. Crivori, P.-A. Carrupt, and B. Testa, "Molecular fields in quantitative structure-permeation relationships: the VolSurf approach," Journal of Molecular Structure: THEOCHEM, vol. 503, no. 1-2, pp. 17-30, 2000.

[21] V. P. Lorenzo, J. M. B. Filho, L. Scotti, and M. T. Scotti, "Combined structure- and ligand-based virtual screening to evaluate caulerpin analogs with potential inhibitory activity against monoamine oxidase B," Brazilian Journal of Pharmacognosy, vol. 25, no. 6, pp. 690-697, 2015.

[22] G. Klopman, J.-Y. Li, S. Wang, and M. Dimayuga, "Computer automated $\log P$ calculations based on an extended group contribution approach," Journal of Chemical Information and Computer Sciences, vol. 34, no. 4, pp. 752-781, 1994.

[23] F. Csizmadia, A. Tsantili-Kakoulidou, I. Panderi, and F. Darvas, "Prediction of distribution coefficient from structure. 1. Estimation method," Journal of Pharmaceutical Sciences, vol. 86, no. 7, pp. 865-871, 1997.

[24] M. L. Raves, M. Harel, Y.-P. Pang, I. Silman, A. P. Kozikowski, and J. L. Sussman, "Structure of acetylcholinesterase complexed with the nootropic alkaloid, (-)-huperzine A," Nature Structural \& Molecular Biology, vol. 4, no. 1, pp. 57-63, 1997.

[25] R. Thomsen and M. H. Christensen, "MolDock: a new technique for high-accuracy molecular docking," Journal of Medicinal Chemistry, vol. 49, no. 11, pp. 3315-3321, 2006.
[26] J. E. Yazal, S. N. Rao, A. Mehl, and W. Slikker Jr., "Prediction of organophosphorus acetylcholinesterase inhibition using threedimensional quantitative structure-activity relationship (3DQSAR) methods," Toxicological Sciences, vol. 63, no. 2, pp. $223-$ $232,2001$. 

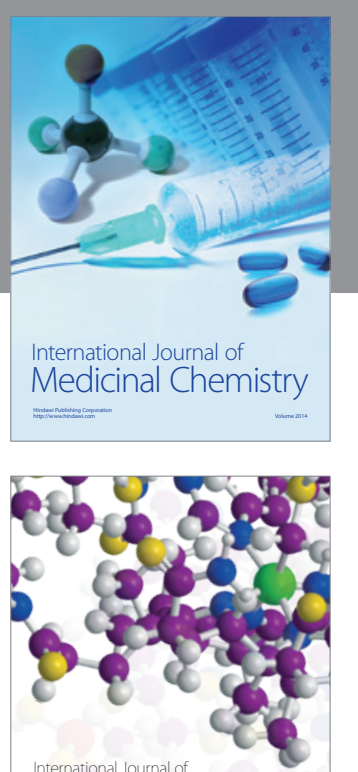

Carbohydrate Chemistry

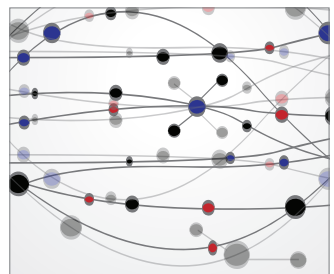

The Scientific World Journal
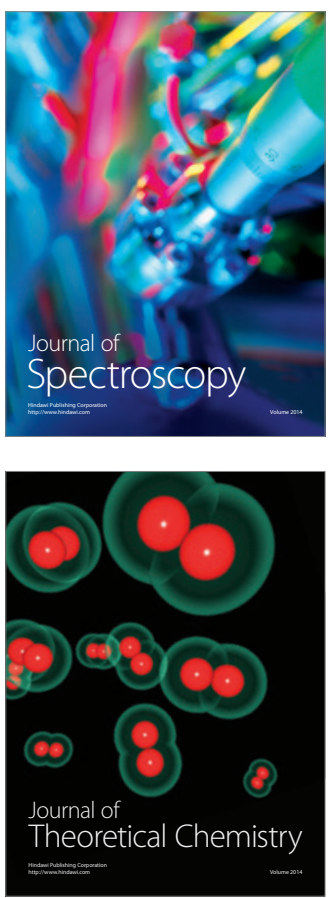
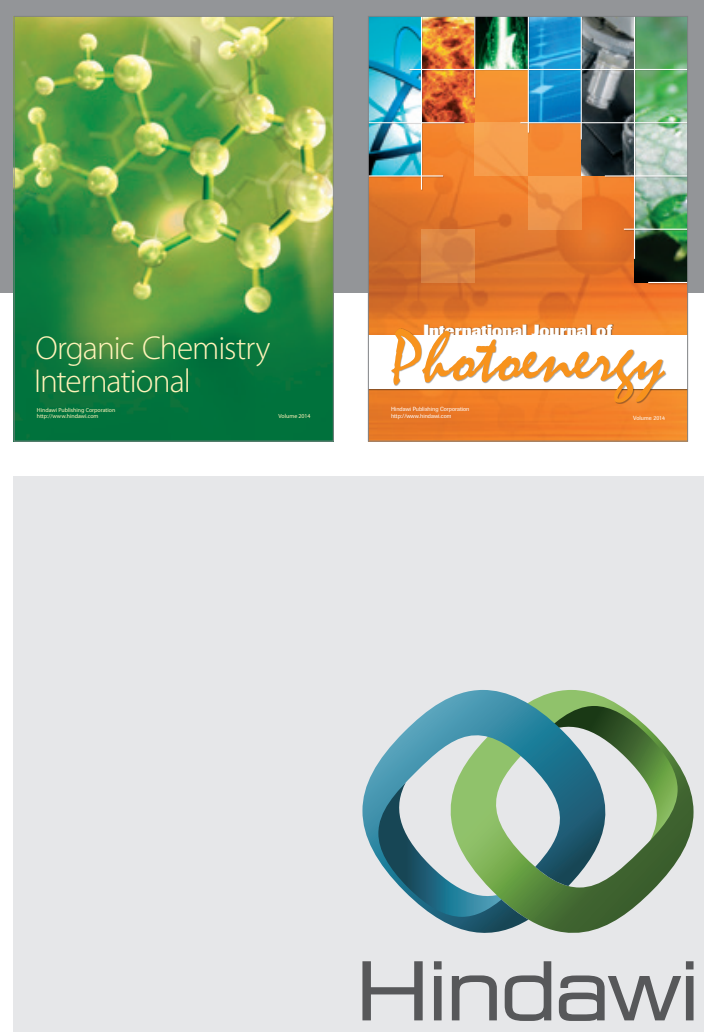

Submit your manuscripts at

http://www.hindawi.com

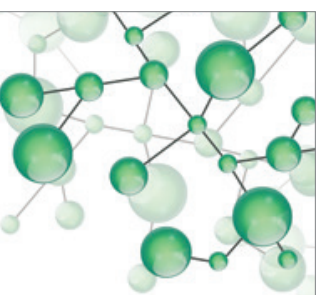

International Journal of

Inorganic Chemistry

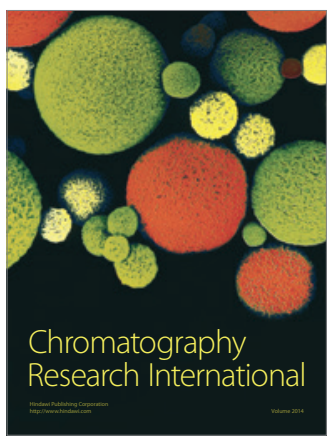

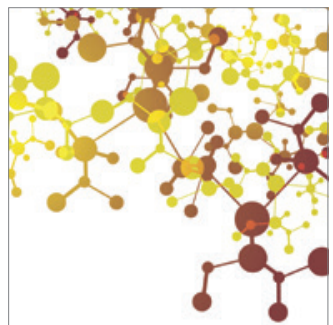

Applied Chemistry
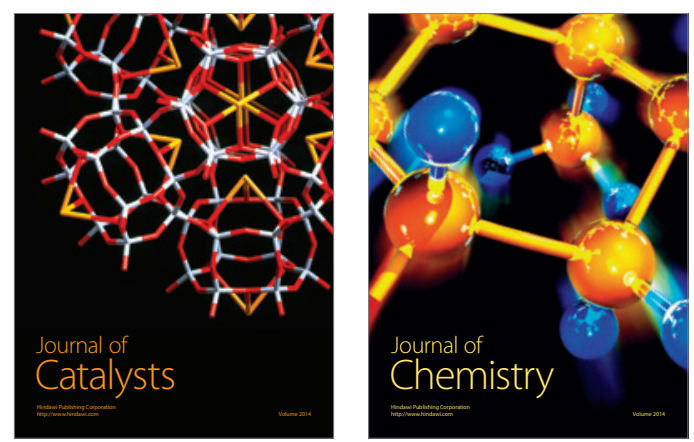
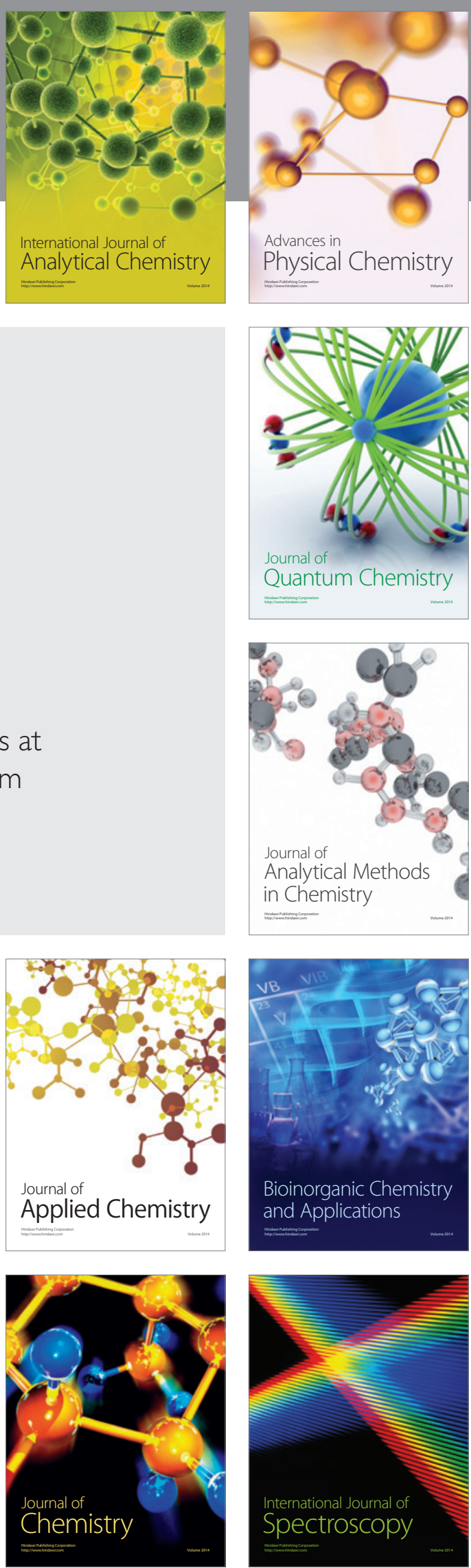